\title{
A Bayesian state-space model to estimate population biomass with catch and limited survey data: application to the thornback ray (Raja clavata) in the Bay of Biscay
}

\author{
Florianne MARANDEL ${ }^{\text {a }}$, Pascal LORANCE and Verena M. TRENKEL \\ Ifremer, rue de l'île d'Yeu, BP 21105, 44311 Nantes Cedex 3, France
}

Received 26 November 2015; Accepted 11 June 2016

\begin{abstract}
The thornback ray (Raja clavata) in the Bay of Biscay is presumed to have declined during the $20^{\text {th }}$ Century. To evaluate this decline and estimate biomass trajectories, a hypothetical catch time series was created for the period 1903-2013. A Bayesian state-space biomass production model with a Schaefer production function was fitted to the hypothetical catch time series and to a shorter research vessel Catch Per Unit Eeffort (CPUE) time series (1973-2013, with missing years). A censored likelihood made it possible to obtain biomass estimates without a CPUE time series or only with an estimate of biomass depletion. A simulation-estimation approach showed a high sensitivity of results to the prior for the intrinsic growth rate. The model provided biomass trajectories which corroborated and quantified the decline of the Bay of Biscay population. The estimated biomass corresponding to the maximum sustainable yield, $B_{\mathrm{MSY}}$, was 32000 tonnes, which is 17 times higher than the estimated biomass in 2014. The biomass estimates obtained without a CPUE time series were highly uncertain. Adding a current biomass depletion observation improved precision, though the biomass time trend was sensitive to this value. Results should be interpreted carefully as several assumptions were necessary to create the long catch time series and to define informative priors, notably for the intrinsic growth rate. Despite this, the results confirm the depleted state of the thornback ray in the Bay of Biscay with the estimated biomass in 2014 being around 3\% of carrying capacity.
\end{abstract}

Keywords: Population dynamics / stock assessment / data poor / censored data / Bayes / thornback ray / state-space model

\section{Introduction}

Several marine fish stocks have strongly declined during the $20^{\text {th }}$ Century as a consequence of overfishing, including certain rays and sharks (Quéro and Cendrero 1996; Dulvy et al. 2014). Global ray and shark landings peaked in 2003, but the recent decrease seems to be more driven by demand rather than being the result of a range of management measures (Davidson et al. 2015). The conservation of rays and shark populations has become a major management objective for ensuring sustainable exploitation of marine resources (Dulvy et al. 2014; Davidson et al. 2015). For numerous populations, available data are restricted to life history traits and landings at species level are often not available (Davidson et al. 2015). In Europe the situation has been improving in recent years with most landings now being declared at the species level (Silva et al. 2012; ICES 2014a). In the Bay of Biscay (ICES Subarea VIII), species-specific reporting of thornback ray has become mandatory since 2009 (EC 2009). However, skates and rays are morphologically similar and variable in their coloration and

a Corresponding author: florianne.marandel@ifremer.fr patterning (Steven 1931; Quéro and Guéguen 1981), regional usages of common names are confusing, and market values are moderate and the same for all species, which makes identification of landings to species level problematic (Silva et al. 2012). Whether catches are similar or much larger than landings due to discarding depends on the species, the gear and the period (Rochet et al. 2002; Silva et al. 2012). However, the effect of ignoring discards is reduced by the fact that skates and rays seem to survive discarding relatively well. Average short term skate survival under commercial fishing conditions was estimated around 55\% (Enever et al. 2009).

In the Northeast Atlantic, stock abundance or biomass of ray and skates is usually not quantitatively estimated and their management relies on indicator trends (ICES 2015). The thornback ray, Raja clavata L. 1758, is one of the more widespread ray species in the Northeast Atlantic and a good example for this data-limited situation. As a consequence, the stock dynamics in the Bay of Biscay remains poorly understood. Nevertheless, thornback ray is currently classified as Near Threatened by the IUCN (2005), the largest threat coming from target and bycatch fisheries; in the Bay of Biscay 
thornback ray is primarily by-caught in various fisheries (ICES 2015).

The thornback ray is a medium-sized ray which is found on sandy seabed throughout shelf areas in the Northeast Atlantic (Du Buit 1974; Quéro and Vayne 2005), from 62 $\mathrm{N}$ down to at least $18^{\circ} \mathrm{N}$ and in the Mediterranean and Black Seas (Quéro and Guéguen 1981; Chevolot et al. 2006). The longest observed thornback ray individual (female) was $107 \mathrm{~cm}$ total length and 14 years old (Holden 1972). Sexual maturity $\left(L_{50}\right)$ of Northeast Atlantic populations occurs at 59 to $73 \mathrm{~cm}$ for males and 70 to $78 \mathrm{~cm}$ for females, depending on the area (Serra-Pereira et al. 2011; McCully et al. 2012). In the Irish Sea, this corresponds to ages at first maturity $\left(A_{50}\right)$ of 3.9 and 5.3 years for males and females respectively (Whittamore and McCarthy 2005). Females spawn between 70 and 170 eggs from February to September with a moderate increase of the number of eggs per year with female size (Holden 1975) and regional differences in fecundity and spawning period (SerraPereira et al. 2011).

Although more biological information has become available in recent years, routine stock assessments are still not carried out for thornback ray (ICES 2015). Nevertheless, available studies suggest severe depletion or evidence of decrease of Northeast Atlantic populations (Dulvy et al. 2000, 2006; Figueiredo et al. 2007; ICES 2015). However, the age composition of catches is not routinely estimated therefore agestructured models cannot be used for stock assessment of the thornback ray in the Bay of Biscay. In contrast, biomass production models are good candidates in this context. Designed to describe population dynamics, they have been widely used for stock assessment and estimation of management reference points for species without age data (e.g., McAllister et al. 2001; Ono et al. 2012; Punt et al. 2015). Production models require only a time series of catches and a Catch Per Unit Effort (CPUE) time series. They are commonly considered as the simplest stock assessment models. Simulations have shown that unreliable reference point estimates were often due to the poor quality of the data rather than to the lack of age structure of the model (Hilborn and Walters 1992).

We implemented a biomass production model using a state-space model (SSM) formulation, which is not uncommon for fisheries models (e.g. Hammond and Trenkel 2005; Ono et al. 2012; Trenkel et al. 2012) and includes both process and observation errors. The process error represents random fluctuations in population size due to variations in recruitment or natural mortality. The observation error includes random sampling variability and catchability variations. Unlike the process error, the observation error can be reduced by improving sampling methods or by gathering more data (Parent and Rivot 2013; Gelman et al. 2014). To fit the model without a CPUE time-series or only a depletion estimate, we used a censored likelihood for the biomass process error. Previously a censored likelihood has been used to handle underreported catch data (Hammond and Trenkel 2005). By using a censored likelihood for the biomass production model and a depletion estimate, the model becomes equivalent to stock-reduction analysis (SRA, Kimura and Tagart 1982; Kimura et al. 1984).

The SSM was implemented in a Bayesian framework to draw inference on biomass trajectories and biological param- eters such as the carrying capacity, and applied to the thornback ray population in the Bay of Biscay. The Bayesian framework provides flexibility for statistical modelling, inference and prediction and allows the integration of different types of information and multiple sources of uncertainty in data and models (Parent and Rivot 2013; Gelman et al. 2014). It differs from the frequentist framework in the way parameters are treated. The Bayesian approach considers parameters as random variables while the frequentist framework considers parameters as fixed values. Bayesian SSM have been widely used in fisheries science (e.g. McAllister and Ianelli 1997; Punt and Hilborn 1997; Robert et al. 2010). In our case, despite a general lack of data, the biology of thornback ray is known well enough to integrate it through informative priors. Several methods exist for obtaining posterior parameter distributions. Among them the Markov Chain Monte Carlo (MCMC) approach, which is commonly used for fisheries stock assessments (e.g. Hammond and Trenkel 2005), can be implemented easily using the freely available software BUGS (Bayesian inference Using Gibbs Sampling) (Thomas et al. 2006). The MCMC inference method is not detailed any further.

To assess the strengths and limitations of the proposed method, a simulation-estimation (SE) analysis was conducted. Widely used within the frequentist framework, SE approaches are less common in the Bayesian framework (Ono et al. 2012). The use of simulated data helps to determine the performance of the method by comparing the true parameter values used in the simulations to the posterior distributions. Three types of scenarios were investigated: scenarios with variation in biological parameters (such as the intrinsic growth rate), scenarios with variation in process and observation errors and scenarios exploring the use of only a final depletion estimate. The SSM was then fitted to thornback ray catch data from the Bay of Biscay for the period 1903 to 2013 together or without a research vessel CPUE time series for the years 1990 to 2013, or a biomass depletion estimate for 2014 .

\section{Material and methods}

\subsection{Data}

\subsubsection{Hypothetical landings}

The longest time series of commercial ray and skate landings available for the Northeast Atlantic comes from the North Sea (Heessen 2003; Walker and Hislop 1998) while historic landings of rays and skates in the Bay of Biscay are unreliable with missing data for several countries in many years and unrealistic temporal patterns until the late 1990s. Therefore, a hypothetical time series of thornback ray landings for the Bay of Biscay was created for the period 1903 to 2013 by assuming that the overall trend between 1903 and 1995 followed that of total ray and skate landings in the North Sea and thereafter the landings collated by ICES were reliable (ICES 2014a). The North Sea landings time series is characterised by strong drops during the two world wars, followed by peaks in landings just after the wars (Fig. 1a). Although landings data for the Bay of Biscay are less reliable than for the North Sea, the effect of reduced fishing has been documented for the Second World War 
a)

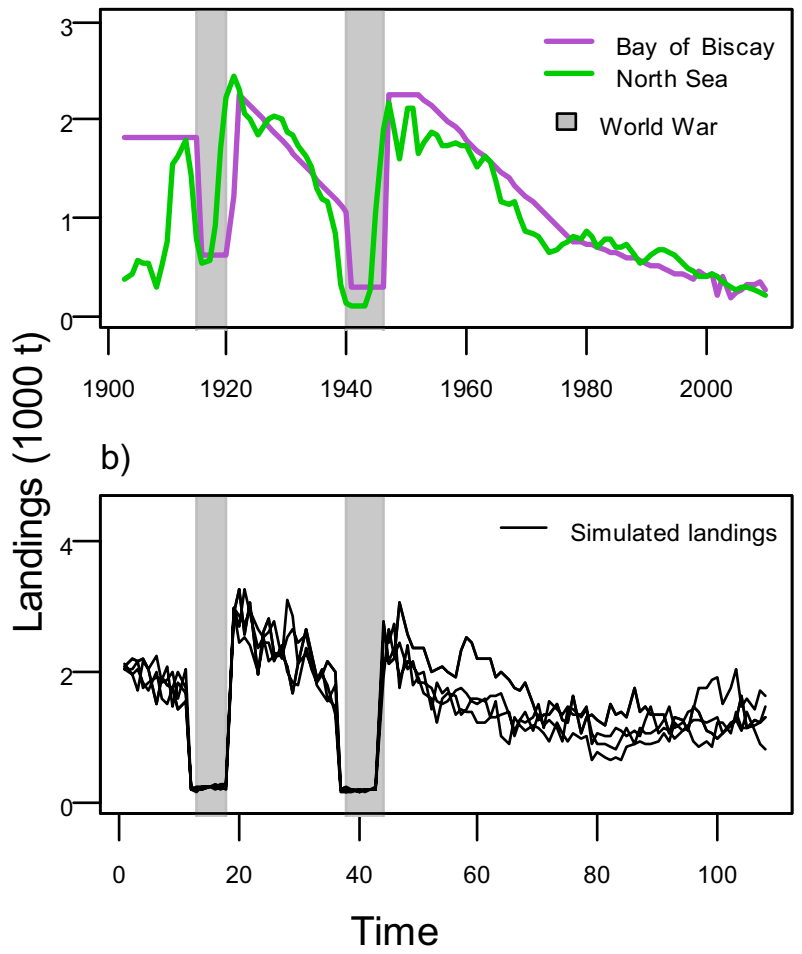

Fig. 1. (a) Hypothetical landings for thornback ray in the Bay of Biscay for the period 1903 to 2013 constructed to mimic total ray and skate landings in the North Sea. Landings peak after both World Wars (grey shaded areas) and decrease gradually thereafter. (b) Example simulated catch time series used for the simulation-estimation approach.

(WWII) with much higher landings after the war, including for rays and skates (Letaconnoux 1948). Landings during the period 1903 to 2000 were approximated by seven periods of stable or monotonously decreasing landings which were connected to create a complete time series. Stable landings were assumed from 1903 to 1913 like in Walker and Hislop (1998), for five years during WWI, for six years during WWII and just after it, but at a higher level. Decreasing landings were assumed between the two wars and after 1950s, with a changing slope in the late 1970s (Fig. 1a). The overall level was set so that landings in 1995 were about the mean of ICES landings in 1996-1999, that is 400 tonnes.

Discards were not included and landings were considered equivalent to catches because the rate of discarding of thornback ray in the Bay of Biscay is not quantified. Thornback ray has always been marketable. Thus historic discards might have been limited to small and damaged individuals. In recent years, discards may have increased as a consequence of restrictive quotas but such discards might at least partly survive (ICES 2014a).

Pauly and Zeller (2016) presented an alternative catch time series for total sharks and rays in the Bay of Biscay for the period 1950 to 2006. Again, several steps were needed to create an alternative hypothetical thornback ray catch time series from this. First, for years before 2006 average landing proportions of the main shark species (spurdog, porbeagle, smooth-hound, tope and catsharks) were calculated from the data held by ICES and then subtracted from the total shark and ray catches to obtain a rays only catch time series. Second, the average proportion of thornback ray in recorded landings was calculated from the ICES data and applied to these "rays" landings. From 2007 onwards species-specific thornback ray landings can be used (ICES 2015). In contrast to the time series created in this study, this alternative thornback ray catch time series shows no time trend since 1950 with catches varying around 500 tonnes (Appendix B). After 1980, both hypothetical catch time series are of the same order of magnitude but the alternative hypothetical catch time series presents higher inter-annual variations. The lack of a general time trend and the higher inter-annual variations make this alternative catch time series more unlikely. Consequently, it was not used in this study.

\subsubsection{Research vessel CPUE}

A research vessel CPUE was calculated using data from the EVHOE bottom trawl survey in the Bay of Biscay between 1987 and 2014 and from surveys carried out in 1973 and 1976. Each survey used the same trawl and sampling protocol but there were some differences in the area and depths covered (see Poulard and Blanchard 2005 and Poulard and Trenkel 2007 for EVHOE survey details). Post-stratification was used by first delineating the area occupied by thornback ray in each year and then calculating the swept area based total biomass in the occupied area. The post-stratified research vessel CPUE was well correlated to the index obtained using the full EVHOE stratification design, which was however not available for years before 1987. As the EVHOE survey was carried out in October-November, the research vessel CPUE of year $t$ was compared to modelled biomass for year $t+1$.

\subsection{State-space model}

\subsubsection{Biomass dynamic}

The biomass dynamics model was based on a discrete-time sequential equation that mimics the biomass dynamics of the population. The biomass at time $t+1\left(B_{t+1}\right)$ depends on the biomass at time $t\left(B_{t}\right)$, the production between times $t$ and $t+1$ and the cumulative catches during the same period. Production was modelled by the Schaefer production function, which integrates biological processes such as recruitment and growth. Following Agnew et al. (2000) the Schaefer function was chosen because of the shape of the stock-recruitment relationship of the species: rays and skates show a close relationship between mature population size and recruitment due to low fecundity of adults and late maturity (Whittamore and McCarthy 2005; ICES 2014b). It has previously been used for elasmobranchs (Walker 1992; Agnew et al. 2000).

The Schaefer production function has two biological parameters: intrinsic growth rate $r$ and carrying capacity $K$, leading to the following state equation where $C_{t}$ represents the catches during year $t$ :

$$
B_{t+1}=B_{t}+r * B_{t}\left(1-\frac{B_{t}}{K}\right)-C_{t} .
$$


Table 1. Model parameters and prior distributions used for the simulation-estimation study and the application to thornback ray in the Bay of Biscay. The BUGS aliases relate to the BUGS code provided in Appendix A.

\begin{tabular}{|c|c|c|c|}
\hline Parameter & Description & Prior & BUGS Alias \\
\hline$r$ & Intrinsic population growth rate & $\begin{array}{c}\text { Beta }(34,300) \\
\text { mean }=0.1, C V=0.16\end{array}$ & r \\
\hline$K$ & Carrying capacity & Uniform $(20000,100000)$ & $\mathrm{K}$ \\
\hline$Y 1903$ & Initial relative biomass in 1903 & $\begin{array}{c}\operatorname{Beta}(17,4) \\
\text { mean }=0.84, C V=0.1\end{array}$ & YQ \\
\hline$Y 2000$ & Initial relative biomass in 2000 & $\begin{array}{c}\text { Beta }(2,6) \\
\text { mean }=0.16, C V=0.6\end{array}$ & YQ \\
\hline $1 / \sigma^{2}$ & Process error precision (inverse variance) & $\begin{array}{c}\text { Gamma }(400,1) \\
\text { mean }=399, C V=0.05\end{array}$ & ytau2 \\
\hline$q$ & Survey catchability & Uniform $(0.01,0.6)$ & $\mathrm{q}$ \\
\hline $1 / \tau^{2}$ & Observation error precision (inverse variance) & $\begin{array}{c}\text { Gamma }(44,2) \\
\text { mean }=22, C V=0.15\end{array}$ & itau2 \\
\hline$C V$ & Uncertainty of landings & 0.2 (constant) & $\mathrm{CV}$ \\
\hline
\end{tabular}

To facilitate model fitting, the model was formulated for relative biomass $Y_{t}=B_{t} / K$ as in Hammond and Trenkel (2005). The relative biomass in the first year is denoted $Y 0$. The process error was assumed to be normally distributed with constant variance $\sigma^{2}$.

$$
Y_{t+1} \sim N\left((r+1) Y_{t}-r Y_{t}^{2}-\frac{C_{t}}{K}, \sigma^{2}\right)
$$

The biomass distribution was truncated at both ends leading to a censored likelihood. Assuming that the mean biomass cannot be much larger than the carrying capacity, the upper bound for $Y_{t}$ was set to $1+3 \sigma$. We can also safely consider that biomass $B_{t}$ was higher than the hypothetical landings, noted $l_{t}$, for a given time period. Moreover, the probability of catching more than half the population in a single year was considered low, leading to the constraints:

$$
\frac{2 l_{t}}{K}<Y_{t}<1+3 \sigma
$$

As the hypothetical landings $l_{t}$ were uncertain but not necessarily biased, catches were modelled by a lognormal distribution with mean equal to the hypothetical landings and the variance corresponding to a constant coefficient of variation $(\mathrm{CV})$ of $20 \%$ :

$$
C_{t} \sim \log N\left(\log \left(l_{t}\right), \log \left(C V^{2}+1\right)\right) .
$$

Maximum Sustainable Yield $(M S Y)$ and corresponding $B_{\mathrm{MSY}}$ were calculated according to the following equations:

$$
B_{\mathrm{MSY}}=\frac{K}{2}, \quad M S Y=\frac{r K}{4} .
$$

\subsubsection{Observation model}

The observation model links population biomass to the research vessel CPUE via a catchability constant $q$. The observation error of the research vessel CPUE $i_{t}$ was modelled with a lognormal distribution and a constant variance $\tau^{2}$, i.e. constant $\mathrm{CV}$. It incorporated sampling variability and random variation in catchability.

$$
i_{t} \sim \log N\left(\log \left(q Y_{t} K\right), \tau^{2}\right)
$$

The observation model was replaced by a truncated normal distribution with variance $\varepsilon^{2}$ when, instead of a research vessel CPUE time series, only an estimate of the depletion level $d_{t}$ was used in year $t$.

$$
d_{t} \sim N\left(Y_{t}, \varepsilon^{2}\right) \quad 0<d_{t}<1
$$

\subsubsection{Prior distributions}

Prior distributions and fixed values for the seven model parameters $\theta=(Y 0, K, r, \sigma, q, \tau, C V)$ are summarized in Table 1. Thornback ray in the Bay of Biscay was exploited before 1903 but not overexploited (Quéro and Cendrero 1996). Therefore, an informative Beta distribution was selected as prior for $Y 0$ (noted $Y 1903$ for the case study) for which $95 \%$ of the probability mass were contained between 0.5 and 1 (Table 1). The informative prior distribution for the intrinsic growth rate $r$ was derived using the Leslie method reviewed in McAllister et al. (2001). The method involved simulating an age-structured population model at equilibrium assuming 140 eggs per year for females 5 years and older, egg-tojuvenile natural mortality of 5 (corresponding to a survival rate of 0.0067 ) and adult natural mortality of 0.1 . Numbers were transformed to biomass using growth parameters $L_{\infty}=118$, $k=0.155$ and $t_{0}=0.655$ (Wiegand et al. 2011) and weightlength parameters $a=0.00000345$ and $b=3.1807$ (Dorel et al. 1998). This provided an $r$ estimate of around 0.105 . To incorporate variability in intrinsic growth rates for elasmobranchs (Camhi et al. 2008; Frisk et al. 2005), an informative Beta distribution was selected for $r$ for which $95 \%$ of the probability mass was contained between 0.05 and 0.15 with the mode at 0.105 (Table 1 ).

A uniform prior distribution was used for the carrying capacity $K$. As this parameter is very population-dependent, it would have been difficult to define an informative prior based on knowledge from other populations. The limits of the uniform distribution are somewhat arbitrary reflecting expert knowledge for the Bay of Biscay population (Table 1). An uniform distribution was also used as prior for catchability $q$ with upper limit 0.5 and lower limit 0.01 , both reflecting expert knowledge and results reported in the literature 
(Fraser et al. 2007). An informative prior distribution was chosen for the precision of the process error $\left(1 / \sigma^{2}\right)$ as the data contains no information on this parameter (Table 1$)$; similarly for the precision of the CPUE time series $\left(1 / \tau^{2}\right)$.

\subsubsection{Bayesian inference}

All computations were performed with the $\mathrm{R}$ platform (v3.1.2, R Foundation for Statistical Computing 2015). OpenBUGS (v3.2.3, Thomas et al. 2006) was used for Bayesian inference and was run within $\mathrm{R}$ using the BRugs package (Thomas et al. 2006). Results were calculated for three parallel MCMC chains, composed of 150000 iterations with different initialization points. The burn-in for each MCMC chain was 40000 iterations and autocorrelation among samples was limited by saving every $100^{\text {th }}$ parameter value. Convergence was checked with several diagnostics including the Gelman-Rubin diagnostic (Gelman et al. 2014), the Geweke convergence diagnostic (Geweke 1992) and an expert appreciation of trace plots created using the package Coda (Plummer et al. 2006). The BUGS code is provided in Appendix A.

\subsection{Simulation-estimation approach}

For the simulation-estimation (SE) approach, time series of catches and biomass were simulated for 111 years as in the case study using equations (1) to (5) as operating model and different sets of parameter values. Model performance was then investigated for two cases. In the first case simulated catches and the research vessel CPUE were used for Bayesian inference. In the second case, catches and only a depletion index for the final year were used.

The SE approach focused on two main issues:

(i) Are the posterior parameter estimates sensitive to the prior distribution used for biological parameters $(r, K)$ ?

(ii) Does the model succeed in correctly estimating the depletion state of the simulated population in the last year? And does it succeed in estimating the underlying biomasses?

\subsubsection{Simulation setup}

Overall fourteen scenarios were investigated (Table 2). Catches used in all scenarios were created to mimic the temporal pattern of the hypothetical time series for thornback ray in the Bay of Biscay (Fig. 1a). Scenarios 1 to 4 aimed at testing the effects on model performance of the values of the biological parameters $r$ and $K$. For this, two values were used for each parameter which were considered realistic for elasmobranchs and were towards the upper and lower end of the respective prior distributions. All other parameters $(q, \tau, \sigma, Y 0$ and $C V)$ had the same value in all four scenarios, referred to as reference values and considered plausible for the Bay of Biscay thornback ray case study (Table 3).

Scenarios 5 to 12 aimed at testing the effects on model performance of the values of the variance parameters $\sigma^{2}, \tau^{2}$ and $\mathrm{CV}$; reference values were used for $r, K, Y 0$ et $q$ for these
Table 2. Description of scenarios used in the simulation-estimation approach. Examples of variable catch time series are provided in Figure 1b. Reference values are summarised in Table 3.

\begin{tabular}{cccccc}
\hline Scenario & $K$ & $r$ & $\sigma$ & $\tau$ & $C V$ \\
\hline Reference & 60000 & 0.105 & 0.05 & 0.2 & 0.2 \\
\hline 1 & 90000 & 0.13 & & & \\
2 & 30000 & 0.08 & & \\
3 & 90000 & 0.08 & \multicolumn{2}{c}{ reference values } \\
4 & 30000 & 0.13 & & & \\
5 & & & 0.03 & 0.2 & 0.1 \\
6 & & & 0.1 & 0.2 & 0.1 \\
7 & & & 0.1 & 0.3 & 0.1 \\
8 & & & 0.03 & 0.3 & 0.1 \\
9 & & & 0.03 & 0.2 & 0.4 \\
10 & reference values & 0.1 & 0.2 & 0.4 \\
11 & & & 0.1 & 0.3 & 0.4 \\
12 & & & 0.03 & 0.3 & 0.4 \\
I & & & reference values \\
II & & & \multicolumn{5}{c}{}
\end{tabular}

Table 3. Reference parameter values used in the simulationestimation approach and posterior mean estimates for thornback ray in the Bay of Biscay (95\% credible interval) from FULL run (landings and research vessel CPUE for the years 1973-2013). In the FULL run, $Y 0$ correspond to the initial relative biomass in 1903, noted $Y 1903$ for the case study.

\begin{tabular}{ccc}
\hline Parameter & Reference value & Thornback ray (CI 95\%) \\
\hline$K$ & 60000 & $63000(42000-94000)$ \\
$r$ & 0.105 & $0.092(0.065-0.12)$ \\
$q$ & 0.15 & $0.13(0.07-0.19)$ \\
$Y 0 \mid Y 1903$ & 0.85 & $0.82(0.63-0.94)$ \\
$\sigma$ & 0.05 & $0.05(0.048-0.053)$ \\
$\tau$ & 0.2 & $0.23(0.19-0.27)$ \\
$C V$ & 0.2 & $0.2($ fixed $)$ \\
\hline
\end{tabular}

scenarios (Table 2). Two realistic values were tested for each parameter. The two values tested for the $C V$ correspond to a maximum (0.4) and a realistic optimistic value (0.1). However, $C V$ was always fixed at 0.2 for inference.

The final two scenarios, denoted I and II, used reference values for all model parameters. The purpose of these two scenarios was to test model performance in the case where only a depletion estimate for the final year (year 111) was available instead of a research vessel CPUE time series. To create a depletion observation $\left(d_{111}\right)$ a random draw from a truncated normal distribution with mean $Y_{111}$ and variance $\varepsilon^{2}$ was carried out:

$$
d_{111} \sim N\left(Y_{111}, \varepsilon^{2}\right) \quad 0<d_{111}<1 .
$$

To evaluate the impact of the observation error, two values were tested for $\varepsilon$ : 0.05 (scenario I) and 0.2 (scenario II).

The model assumed catches were known. To simulate a time series of catches with lognormal observation error, variable exploitation rates $(0.005-0.07)$ were applied to the simulated biomass of each year and a random draw was carried out from a lognormal distribution with the resulting values as means and coefficients of variation equal to the value of the parameter $C V$. The values of the exploitation rates were chosen by hand to achieve the desired temporal pattern 
and comparable magnitude. For scenarios 1 to 12 , a research vessel CPUE time series was simulated for the last 29 years to reflect the data available for the case study. For scenarios I and II a depletion index for the final year was simulated. For all scenarios, 100 replicates were generated. Initial analyses showed that 100 replicates were enough to reliably evaluate performance; performance measures stabilised at around 30 replicates (results not shown).

The simulated catches and research vessel CPUE time series (or depletion index) together with the prior distributions listed in Table 1 were used for Bayesian inference. For all simulations, the model used for the estimation was the same as the operating model used for simulations; this condition ensured that any differences between simulations and estimation were due to estimation performance only.

\subsubsection{Performance assessment}

The performance of the estimation method was assessed with three complementary criteria chosen to represent how well the estimated parameter values $\hat{\theta}_{s}$ (posterior means) of replicate $s(s=1, \ldots, 100)$ agreed with the true parameter values $\theta_{S C}$ of the scenario (Table 2). First, the Mean Relative Error (MRE) was calculated to quantify the bias of Bayesian estimation for each of the 14 scenarios (SC). A negative MRE value means that globally the model tended to underestimate the parameters value and a positive value means overestimation.

$$
\operatorname{MRE}\left(\theta_{S C}\right)=\frac{1}{100} \sum_{s=1}^{100}\left(\frac{\hat{\theta}_{s}-\theta_{S C}}{\theta_{S C}}\right) .
$$

Second, the Mean Squared Error (MSE) was calculated to measure precision of Bayesian posterior mean estimates for each parameter and scenario:

$$
\operatorname{MSE}\left(\theta_{S C}\right)=\frac{1}{100} \sum_{s=1}^{100}\left[\left(\hat{\theta}_{s}-\theta_{S C}\right)^{2}\right] .
$$

Finally, the Median of Absolute Relative Error was calculated which quantifies "average" model precision if the model is correct (Ono et al. 2012), where $\hat{\theta}_{s}^{\prime}$ is the posterior median of replicate $s(s=1, \ldots, 100)$. The smaller the value, the more precise are the parameter estimates on "average".

$$
\operatorname{MARE}\left(\theta_{S C}\right)=\operatorname{median}\left(\left|\frac{\hat{\theta}_{1}^{\prime}-\theta_{S C}}{\theta_{S C}}\right|, \ldots,\left|\frac{\hat{\theta}_{100}^{\prime}-\theta_{S C}}{\theta_{S C}}\right|\right) \text {. }
$$

\subsection{Application to thornback ray in the Bay of Biscay}

The model was applied to the thornback ray in the Bay of Biscay using the priors defined in Table 1.

Four runs were made using different data combinations and time periods to explore the importance of the different data types. For the full run (FULL), the full hypothetical landings time series (1903-2013) and research vessel CPUE time series (1973, 1976, 1987-2013) were used in the model. To avoid having to make too many assumptions for reconstructing the catch time series a run (SHORT) restricted to the recent time period (2000-2013) was also carried out. For this run the prior $Y 2000$ was used instead of that for $Y 1903$ (see Table 1). The landings only run (LANDINGS) represented the case where no research vessel CPUE was available or where it was deemed unusable due to poor quality. The fourth run (DEPLETION) represented a situation where no research vessel CPUE but an estimate of the final depletion level $d_{2014}$ was available. Given thornback ray in the Bay of Biscay is thought to be overexploited, a relatively small value was chosen $\left(d_{2014}=0.1\right)$ with a small standard deviation $(\varepsilon=0.05)$. These values are somewhat arbitrary but the aim was to compare the biomass trajectories obtained with a research vessel CPUE and with only information for the depletion level in the final year.

\subsection{Posterior predictive check}

For an overall assessment of the FULL run, we examined how well the fitted model could reproduce the available research vessel CPUE time series. We simulated 3000 CPUE time series using parameter values drawn from the joint posterior distribution, hypothetical catches and the model (Eqs. (1)(6)). The distribution of simulated CPUEs was then compared with the observed research vessel CPUE time series.

\section{Results}

\subsection{Simulation-estimation approach}

For all replicates of all scenarios the population never crashed; moreover biomass trajectories never hit the lower bound $\left(2 l_{t} / K\right)$. Averaged across scenarios 1 to 12 , estimates of parameter $r$ had the smallest mean MRE and second smallest MARE ( -0.013 and 0.105 respectively), followed by $Y 0$ (MRE -0.05; MARE 0.04), $\tau$ (MRE -0.054; MARE 0.118), $\sigma$ (MRE 0.055; MARE 0.389), $K$ (MRE 0.15; MARE 0.17) and $q$ (MRE 0.17; MARE 0.35). The parameter $C V$ was not estimated though the true value was varied for certain scenarios. The MRE and MSE values for parameters $K, r, Y 0, \sigma$ and $\tau$ were negatively correlated, while they were positively correlated for $q$ (not shown). For scenarios 1 to 12, results for performance measures MRE, MSE and MARE are detailed in Table 4.

The estimation quality of parameter $K$ varied between scenarios depending on whether the true value of $K$ was larger than the mean of the prior uniform distribution (MRE negative; scenarios 1 and 3), smaller (MRE positive; scenarios 2 and 4) or equal to the mean (small positive MRE; scenarios 512) (Table 4, Fig. 2a). The highest overestimation was found for scenario $4(\mathrm{MRE}=0.5)$; this scenario combined low $r$ with low $K$ values. For this scenario the MRE corresponded exactly to the relative difference between the mean of the prior and the true value. The complementary scenario 1 (true $r$ and $K$ above mean of priors) had the smallest MRE of all tested scenarios. For all scenarios, except scenario 4, MRE values were smaller than the relative difference between true value and the mean of the prior for $K$, indicating that the data of these scenarios contained information on the parameter. 


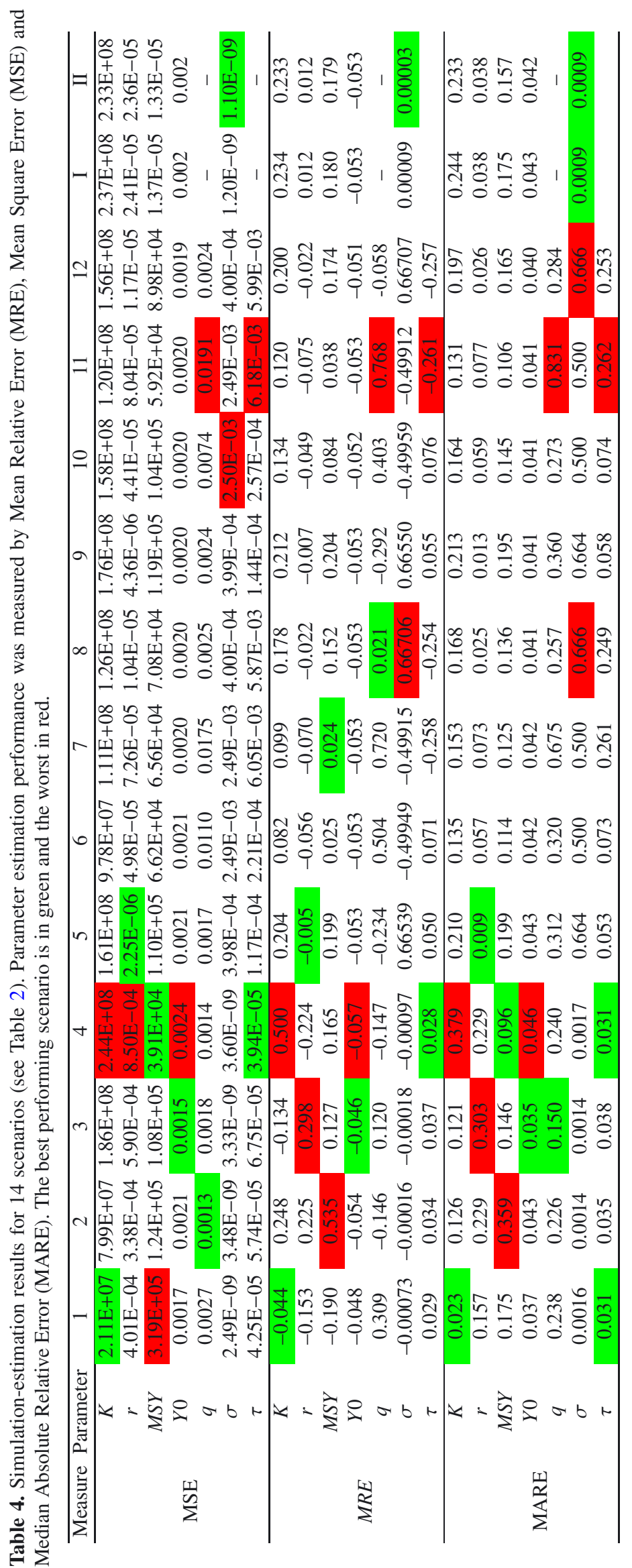




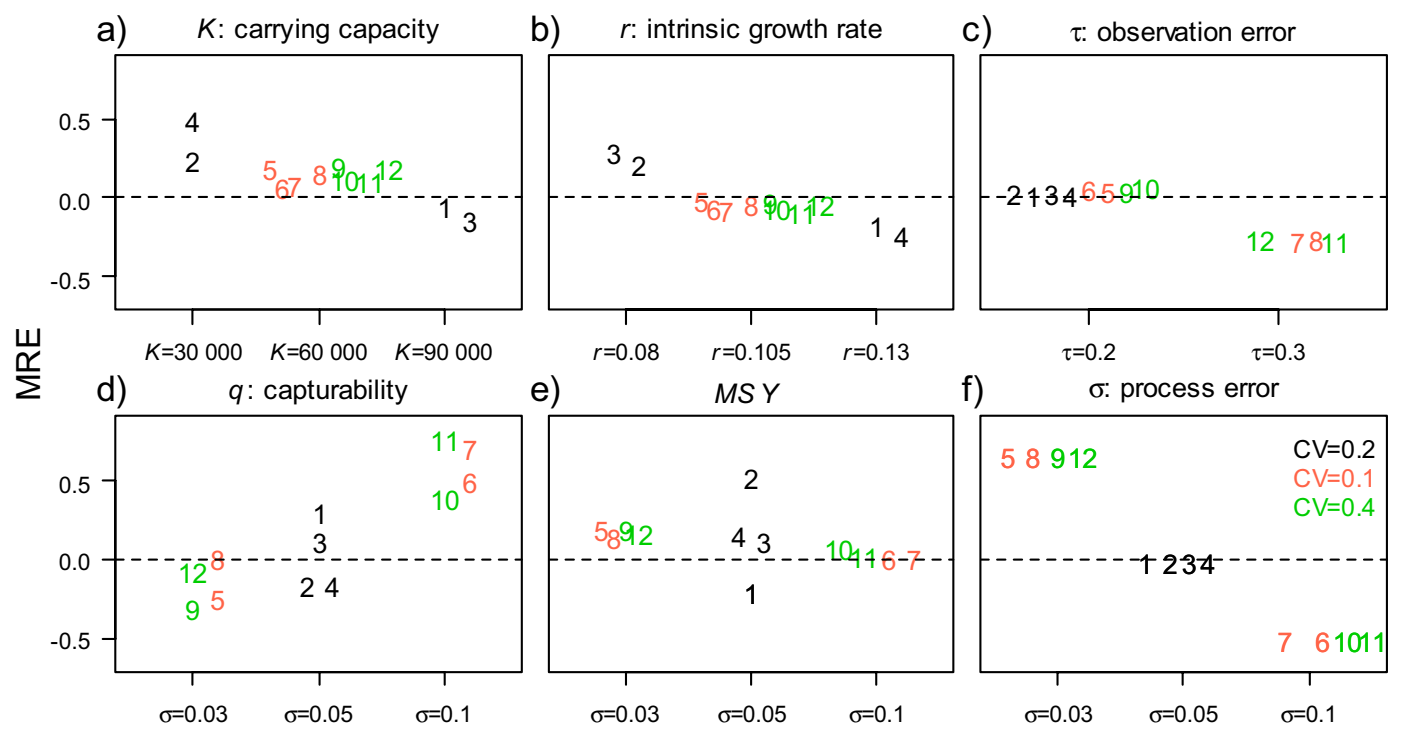

Fig. 2. Model performance criteria for scenarios 1 to 12 tested in the Simulation-Estimation study. Performance was measured by Mean Relative Error ( $y$-axis) and plotted separately for different true model parameters values.

As for $K$, estimates of $r$ can be separated into three categories according to the difference between the true value and the mean of the prior (Table 4, Fig. 2b): in scenarios 1 and 4 (true $r$ value $>$ mean of prior) the parameter was underestimated. In scenarios 2 and 3, with low true value, the parameter was overestimated. In general, estimates of $r$ were driven by the prior and the parameter was hard to estimate though in all cases posteriors were shifted in the correct direction. As expected, MRE values for $r$ and $K$ were negatively correlated (Pearson, $p$-value $=0.06$ ), except for scenarios 1 and 2 . These scenarios correspond respectively to the scenario with high $K$ /high $r$ values and scenario with low $K /$ low $r$ values. The derived quantity $M S Y$ was estimated using the posterior estimates of $r$ and $K$. It was generally overestimated, with the poorest performance obtained for scenario 2 (low $r$ and low $K)$. Estimates of $M S Y$ with smallest bias (MRE < 0.1) were obtained for scenarios (namely 6, 7,10 and 11) which had high process errors $\sigma$ (0.1) (Fig. 2e).

Estimation performance of parameter $q$ varied between scenarios (Table 4). MRE increased with the process error $\sigma$, with strongly positively biased estimates for scenarios 7 and 11 (MRE $>0.5$ ) (Fig. 2d). Thus larger process error made $q$ more difficult to estimate. The initial relative biomass $Y 0$ was generally well estimated with little differences between scenarios (Table 4). This is reassuring but not surprising given the true value was equal to the mean of the prior. Hence the simulations did not provide much insight into the identifiability of this parameter.

Globally, performance for parameter $\sigma$ was driven by the difference between the prior and the true value (Fig. 2f). However, for small true values $(0.03)$ the magnitude of MRE values was larger than the relative difference between the true value and the mean of the prior. This indicates that for small values of $\sigma$, posterior estimates were less biased. Parameter $\tau$ (Fig. 2c) was globally more estimable than $\sigma$ and presented the lowest bias. In the scenarios (namely $7,8,11$ and 12) in which the true value was $50 \%$ larger than the mean of the prior
( 0.3 and 0.2 , respectively), the MRE was around 0.25 , indicating a relative estimation bias of only $25 \%$. Using larger values for $C V$ (catch uncertainty) only slightly decreased model performance. MRE values were on average 3\% larger for scenarios 9 to 12 with $C V=0.4$ compared to scenarios 5 to 8 with $C V=0.1$, with differences between parameters. The difference was $11 \%$ for MSE and $4 \%$ for MARE.

For scenarios I and II, using reference parameter values and a final year depletion index, posterior distributions presented updates of the prior distributions for all parameters except for the process error $\sigma$. Both scenarios performed similarly, with an overestimation of $K, r$ and $Y 0$ and a very small underestimation of $\sigma$. Performance metrics for $K$ were comparable to those obtained for scenarios 1 to 12 . The amount of observation error assumed for the final depletion level observation did not influence the quality of inference. Thus model performance achieved when using only a depletion estimate for the final year was comparable to that using a 24 years time series of biomass indices.

\subsection{Application to thornback ray in the Bay of Biscay}

\subsubsection{FULL run: landings (1903-2013) and research vessel CPUE (1973-2013)}

In this run, all available data were used for the estimation. The marginal posterior distributions of all parameters were updated compared to the prior distribution except for $Y 1903$ (Fig. 3), $\sigma$ and $\tau$ (not shown). The posterior mean of carrying capacity $(K)$ was estimated to be around 63000 tonnes (Table 3) and the intrinsic growth rate $(r) 0.093$, which is slightly lower than the prior derived from the Leslie method $(0.105)$. The marginal posterior distribution of the relative initial biomass (Y1903) was almost identical to the prior distribution, with a mode at 0.82 . The posterior for catchability (q) showed a strong update with a mean of 0.12. MSY was 


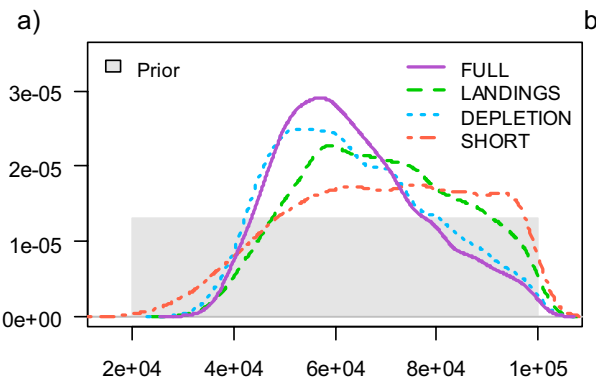

b)
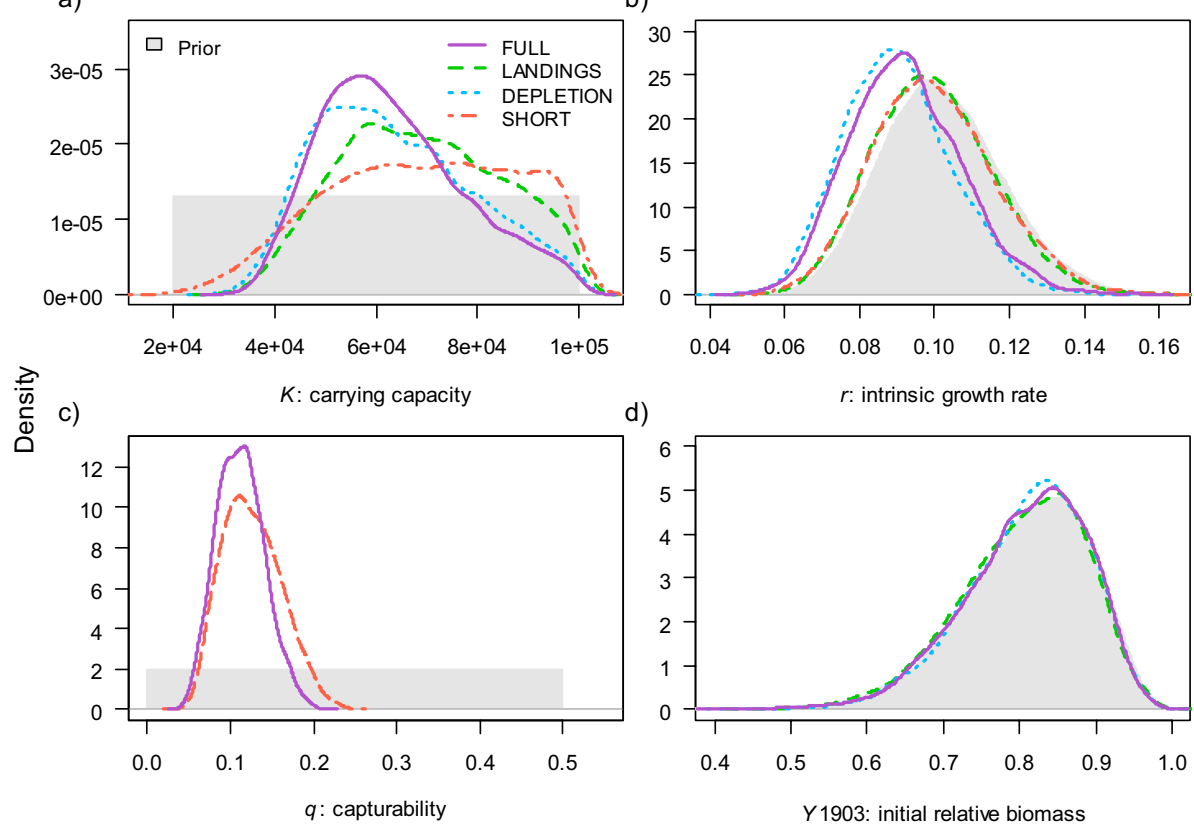

d)

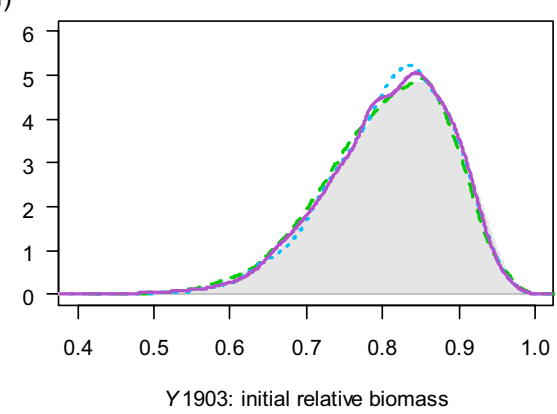

Fig. 3. Comparison of prior and marginal posterior parameter distributions for thornback ray in the Bay of Biscay for four model runs using different data combinations. FULL: landings and research vessel CPUE for the years 1973-2013; LANDINGS: landings only; DEPLETION: landings and final year depletion rate; SHORT: as in FULL but using data for years 2000-2013 only.

estimated at around 1440 tonnes (CI 95\%: 930-2 100). The analysis of the pairwise joint distributions of the four key parameters revealed significant negative correlation between $K$ and $r, K$ and $q$ and $Y 1903$ and $K$, and non-significant positive correlation between all other parameter pairs (Pearson product moment correlation: -0.6 to 0.03 with $p$-value $>0.05$ ) (Fig. 4 ).

The influence of the catches and research vessel CPUE time series on the estimated biomass trajectory as well as the world wars' pattern is clearly visible in Figure 5a. The posterior distribution of biomass estimates was much tighter in recent years for which biomass indices were available. The 2014 biomass was estimated to be around 1900 tonnes (CI 95\%: 940-2 400) which represents 3\% of the estimated carrying capacity.

\subsubsection{SHORT run: landings (2000-2013) and research vessel CPUE (2000-2013)}

In this run, only data for the last 14 years were used for estimation. The marginal posterior distributions of all parameters except $\sigma$ and $\tau$ were updated compared to the prior distributions (orange lines, Fig. 3). The posterior mean of carrying capacity $(K)$ was estimated to be around 68000 tonnes (CI 95\%: 34000-98000) and the intrinsic growth rate $(r) 0.099$ (CI 95\%: 0.069-0.13), which is again lower than our preliminary estimate but higher than the value obtained in the FULL run. The marginal posterior distribution of the relative initial biomass (Y2000) presented a mode at 0.08 (CI 95\%: 0.02 $0.17)$. The posterior for catchability $(q)$ showed a strong update with a mean of 0.13 (CI 95\%: 0.07-0.2). MSY was estimated around 1700 tonnes (CI 95\%: 760-2800) which is 300 tonnes higher than for the FULL run. The biomass in 2014 was estimated around 1900 tonnes (CI 95\%: 760-3600) which rep- resents $3 \%$ of the estimated carrying capacity as in the FULL run (Fig. 5b). The analysis of the pairwise joint distributions of the four key parameters revealed no significant correlations between parameters $K$ and $r$, and $r$ and $q$ (Pearson product moment correlation: 0.007 and 0.03 with $p$-value $>0.05$ ). Low significant correlation was found between all other parameter pairs (Pearson product moment correlation: 0.02 to -0.09 with $p$-value $<0.05)$ except for parameters $K$ and $q$ which were not correlated (Pearson product moment correlation: -0.76 with $p$-value $>0.05)$.

\subsubsection{LANDINGS run}

In this run, only the full time series of hypothetical landings was used but no CPUE. Analysis of the marginal posterior distributions showed lower update of prior distributions compared to the FULL run, in particular for $K$ (green dashed line, Fig. 3). The posterior mean carrying capacity was estimated to be higher at around 70000 tonnes (CI 95\%: 41000 $98000)$ while the intrinsic growth rate was around 0.1 (CI 95\%: 0.07-0.13), which is similar to the mode of the prior. The posterior distribution of the relative initial biomass $Y 1903$ was identical to its prior distribution. $M S Y$ was estimated to be around 1700 tonnes (CI 95\%: 1000-2600). Analysis of the pairwise joint posterior distributions showed relatively low correlations $(-0.3$ to $0.007, p$-value $<0.05)$, with the largest negative value $(-0.3, p$-value $<0.001)$ between $r$ and $K$. The estimated biomass trajectory first decreased and then increased after 1960 (green solid curve, Fig. 5). The biomass in 2014 was estimated to be around 55000 tonnes (CI 95\%: 22 000-87 000) which represents $79 \%$ of the estimated carrying capacity of this run. 

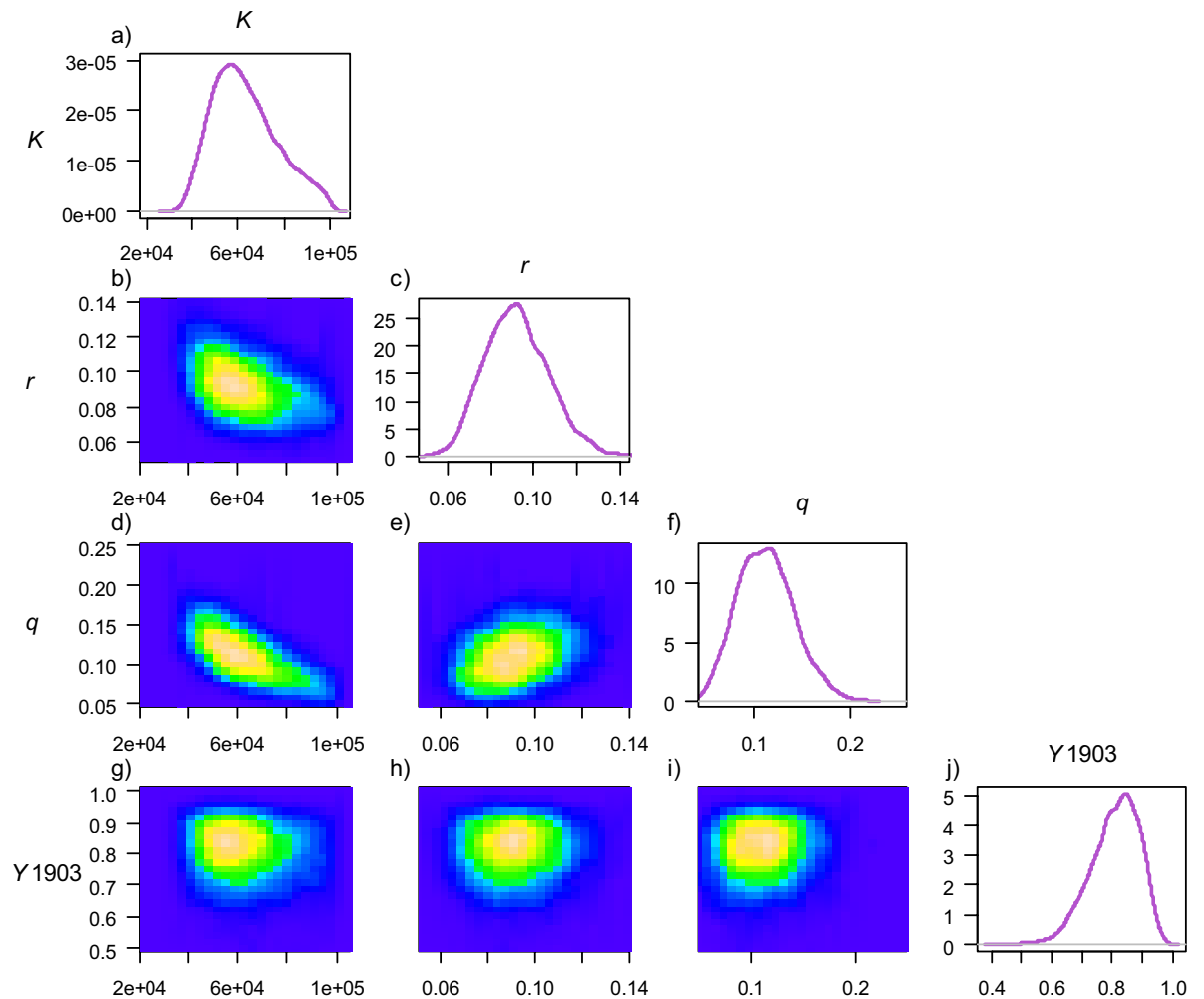

Fig. 4. Results for FULL run for thornback ray in the Bay of Biscay. Joint posterior (density surfaces) and marginal posterior distributions (lines) for main model parameters. $K$ carrying capacity. $r$ intrinsic growth rate. $q$ survey catchability and $Y 1903$ relative initial biomass. The colour scales goes from low values (blue) to high values (orange).

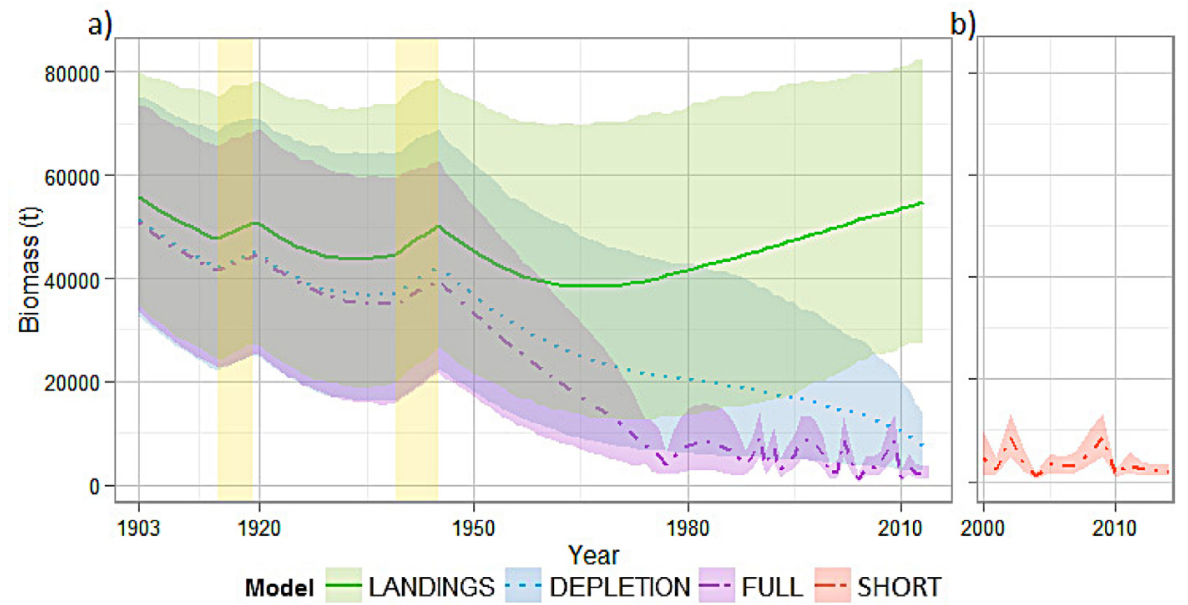

Fig. 5. (a) Estimated biomasses trajectories for thornback ray in the Bay of Biscay for model runs using different data series. LANDINGS: landings only; DEPLETION: landings and final year depletion rate; FULL: landings and research vessel CPUE for the years 1973-2013. Coloured areas: credible intervals between $2.5^{\text {th }}$ and $97.5^{\text {th }}$ percentiles. Vertical rectangles: World War I and II periods. (b) Estimated biomasses trajectories for thornback ray in the Bay of Biscay obtanied using only catches and research vessel CPUE time series from 2000 to 2013 (SHORT run).

\subsubsection{DEPLETION run}

In this run, an estimate of the final (2014) depletion level in addition to landings was used. Comparison of prior and posterior distributions showed a slightly better update for $K$ compared to the LANDINGS run while the posterior for $r$ was shifted to the left (blue dotted line, Fig. 3). The mean posterior carrying capacity was around 64000 tonnes (CI 95\%: 40000
96000 ) and the intrinsic growth rate 0.09 (CI 95\%: 0.07-0.12). $M S Y$ was estimated around 1400 tonnes (CI 95\%: 900-2 100). Analysis of the pairwise joint posterior distributions showed again low correlations $(\sim 0.05, p$-value $>0.05)$ except between $r$ and $K$ for which it was -0.45 ( $p$-value $<0.001)$. The estimated biomass trajectory showed a continuous decline (blue dotted curve, Fig. 5). The 2014 biomass was estimated around 
7500 tonnes (CI 95\%: 2500-15000) which corresponds to $11 \%$ of the estimated carrying capacity.

\subsubsection{Comparison}

The data used for the four model runs contained variable amounts of information which led to different degrees of update of prior parameter distributions (Fig. 3). The largest update was achieved when all data were used (FULL run), while the landings only (LANDINGS) run contained very little information. Posterior mean estimates of carrying capacity varied little between runs (63000-70000 tonnes), similar for estimates of the intrinsic growth rate (0.09 to 0.10). Posteriors of $K$ and $r$ were negatively correlated in all runs, with the highest negative correlation for the depletion (DEPLETION) run and the lowest for the FULL run. This shows that the identifiability of the two parameters increased as more data was used, i.e. the two parameter estimates became less confounded. Posterior distributions for $Y 1903$ were relatively similar for the three runs which included this parameter, which is not surprising given the posteriors were identical to the prior distribution. The parameter $q$ was present only in the FULL and SHORT runs and had identical posterior mean of 0.13 .

The shape of the biomass trajectory was similar for the three long runs before 1950 but after this date each run lead to a different assessment of the dynamics of the thornback ray population in the Bay of Biscay. The LANDINGS run led to an unrealistic biomasses trajectory where recent biomass levels were similar to 1903 biomass levels. This run also had the largest credible intervals for biomass estimates (Fig. 5a). The FULL and SHORT runs provided more precise biomass estimates but implied the strongest depletion and hence the worst current state of the population.

Biomass trajectories for the FULL run (Fig. 5a) were similar to those for the SHORT run (Fig. 5b). Estimates for parameters $M S Y, K$ and $q$ were also similar but with higher uncertainty for the SHORT run. The estimate for $r$ was lower in the FULL run. Both models presented no update for parameters $\sigma$ and $\tau$. In the SHORT run, there was a large update of $Y 2000$ with a posterior mean of 0.08 instead of 0.2 for the prior; there was no update for $Y 1903$ in the FULL run.

\subsection{Posterior predictive check}

A posterior predictive check was carried out for the FULL run only. For this 3000 biomass trajectories were simulated using the joint posterior distribution of model parameters. The model reproduced the data for $7 \%$ of the simulated biomass trajectories which, gathered, shape the one estimated for thornback ray in the Bay of Biscay (Figs. 5a and 6a). However, the model also simulated very different biomass trajectories and among them, 22\% lead to a final biomass above 60000 tonnes i.e. above the estimated carrying capacity (green trajectories in Fig. 6).

Two patterns can be distinguished in the simulated biomass trajectories. The first one presented an increase in biomass after 1977 which corresponds to a change in the catch time series trend (green trajectories in Fig. 6a). They corresponded
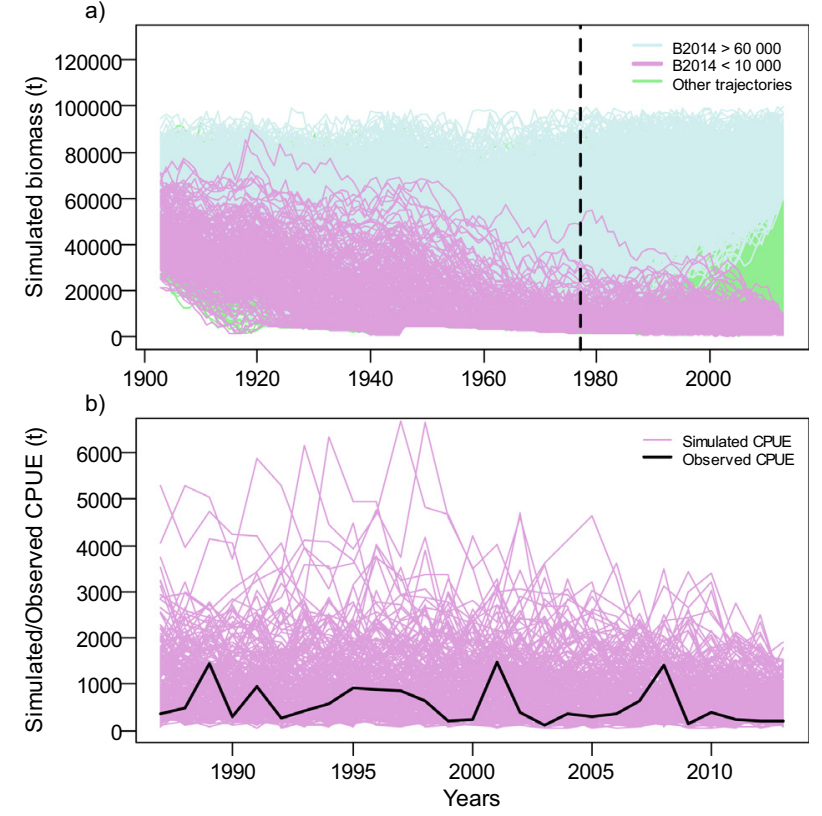

Fig. 6. Results for posterior predictive check for FULL run for thornback ray in the Bay of Biscay. (a) Simulated biomass trajectories. (b) Simulated CPUE trajectories for stock biomass B2014 < 10000 (purple lines in (a) and research vessel CPUE time series (black line). In (a) the vertical line corresponds to the year 1977 where a shift in the blue trajectories is notable. In blue, biomass trajectories for which the biomass in 2014 (B2014) is above 60000 tonnes. In purple, biomass trajectories for which the biomass in 2014 is below 10000 tonnes. All others simulated trajectories are represented in green.

to relatively high carrying capacities around 80000 tonnes (min: 54000 tonnes and max: 107000 tonnes). Values of $r$ used in these trajectories varied between 0.04 and 0.14 . The second pattern corresponded to trajectories which decreased over the whole period (purple trajectories in Fig. 6a). They corresponded to low and medium carrying capacities around 60000 tonnes (min: 25000 tonnes and max: 99000 tonnes). Values of $r$ creating these trajectories also varied between 0.04 and 0.13 . The values for $Y 0$ were similar for the two patterns (around 0.73).

The simulated research vessel CPUE time series corresponding to biomass in 2014 below 10000 tonnes were comparable in magnitude and time trend to the research vessel CPUE time series used in the estimation (Fig. 6b). Thus, the fitted model reproduced the observed data even though only around $7 \%$ of the trajectories showed the same pattern and magnitude.

\section{Discussion}

\subsection{Bayesian state space model}

The Bayesian SSM used in this study made it possible to include different sources of information while accounting for observation uncertainty and natural variability. The inclusion of expert knowledge can be divided into two types: censored 
likelihood and informative priors. The censored likelihood improved the calculation time and the general performance of the model. It also allowed fitting the model without a research vessel CPUE. Biological knowledge was used for deriving an informative prior of the intrinsic growth rate.

For elasmobranchs the relationship between stock size and recruitment is rather linear, owing to their reproductive strategy of low fecundity and high per-offspring investment (Hoening and Gruber 1990). Despite being "the simplest production function" (Hilborn and Walters 1992), the Schaefer model is well suited for this case. It also fitted the data well and led to reasonable estimates for $r$ and $K$.

The SE study with inferences based on catches and a research vessel CPUE (scenarios 1 to 12 ) showed the sensitivity of model results to prior distributions, i.e. the effect of differences between the mode of the prior and the true value. For scenarios using low $K$, the bias in estimates of $K$ was positive and lower than 0.25 except for scenario 4 (low $r$ low $K$ ) for which the bias was highly positive. This indicates that the estimates of $K$ obtained for thornback ray in the Bay Biscay, obtained with the set of priors used in this study, could be biased to some extent. Further, posterior distributions for $r$ were generally similar to prior distributions leading to an underestimation of $r$ for scenarios where the true value was larger than the mode of the prior. This indicates that the data contained little information on this parameter. For the thornback ray case study this means that all inference is conditional on the chosen prior distribution for $r$. Parameters $\sigma$ and $\tau$ were not really estimable but their values did not influence the estimates of other parameters. The SE protocol was created to mimic the available data. Hence, twenty nine years of biomass indices were used and the influence of the duration of the time series was not explored. SE results for the case with limited data (depletion index for the last year only, scenarios I and II) showed that this can change the overall trend of the estimated biomass trajectory, as was indeed found for the thornback ray case study. More work would be required to determine the minimum length of a research vessel CPUE time series needed to obtain reliable biomass estimates. However, model performance was comparable to the case of using no research vessel CPUE time series. This is encouraging for real world applications, if a depletion estimate is available with reasonable precision.

In summary, the SE approach provided general insights with respect to the applicability of the Bayesian SSM to thornback ray in the Bay of Biscay: possible overestimation of the carrying capacity and inference conditional on prior for intrinsic growth rate. Further, the model is not sensitive to the amount of process error $(\sigma)$, observation error $(\tau)$ or uncertainty in landings $(C V)$. However, the SE results should not be overinterpreted. First, the operating model was identical to the SSM used for estimation. Thus robustness to model misspecification was not tested. Second, for two parameters ( $q$ and $Y 0)$ only one value was used for the simulations.

\subsection{Thornback ray in the Bay of Biscay}

With the decline in catches of stocks traditionally targeted, elasmobranchs have become increasingly exploited by com- mercial fisheries leading to global catches peaking in the early 2000s (Davidson et al. 2015). Despite this, only few stock assessments of elasmobranchs stocks have been carried out (Bonfil 1994; Agnew et al. 2000). Some attempts to assess thornback ray stocks have been made (Heessen 2003), but none to the best of our knowledge for the Bay of Biscay mainly due to lack of data. In this study we tried to overcome this situation by creating a hypothetical landings time series and by using a Bayesian approach which made it possible to integrate biological knowledge in addition to the data. The hypothetical landings time series is of course highly uncertain but we partially accounted for this by modelling errors in catches (Eq. (4)). Further, the alternative catch time series was of similar magnitude for the last four decades, hence would have given similar results for that period.

Assuming the hypothetical landings were reasonable, a condition relaxed below, the results indicated that the Bay of Biscay population of thornback ray has steadily declined since the start of the $20^{\text {th }}$ Century. Using all available data (FULL run), the current biomass was estimated as $7 \%$ of the carrying capacity and $B_{\mathrm{MSY}}$ as 32000 tonnes $(50 \%$ of $K$ ). Cope et al. (2015) derived an empirical relationship between species vulnerability to fishing and depletion rate of (more or less) unmanaged stocks for the US Pacific coast. For thornback ray in the Celtic Sea, McCully et al. (2015) estimated a vulnerability score of 1.61. For this level of vulnerability the empirical relationship of Cope et al. (2015) gives a depletion rate of 0.54 . If our estimates are correct, the depletion of thornback ray in the Bay of Biscay is rather severe, suggesting either vulnerability to fishing is higher than in the Celtic Sea or that unmanaged fishing pressure was much higher than on US Pacific coast, or both. The posterior predictive check revealed that this scenario of high depletion is plausible but not the most likely to happen with the biological parameters estimated with the model. However, if the research vessel CPUE time series is trustworthy, the estimated biomass trajectory should be reliable. Further, the FULL and SHORT runs led to very similar biomass trajectories and parameter estimates which indicated that the estimated depletion state was primarily driven by the research vessel CPUE and not too dependent on uncertain historical landings. Hence, the hypothetical landings need only be reasonable for the period 2000 to 2013 for the estimates for thornback ray in the Bay of Biscay to be considered reliable. Trials showed that the estimation did not converge when the time series was reduced to the period for which no landings had to be reconstructed (2010-2013).

In all runs except the one using only a catch time series, the estimated biomass of thornback ray in the Bay of Biscay was below $B_{\text {MSY }}$ during the whole second half of the $20^{\text {th }}$ Century. Even the most optimistic estimates (run with landings only) showed exploitation above $M S Y$ during 35 years in the $20^{\text {th }}$ Century. The FULL run assessment is in line with previous evaluations of a decline of the thornback ray population in the Bay of Biscay (Maurin 1994). There is historical evidence for the recovery potential of thornback ray (Letaconnoux 1948) but in the Bay of Biscay, the potential for a fast rate of recovery seems compromised by the low value of $r$.

In the Bay of Biscay, the only management of thornback ray is the Total Allowable Catch (TAC) set for all Rajiformes 
combined for the Bay of Biscay and West Iberian waters (ICES subarea VIII and IX). This TAC was introduced in 2009 only. Our study of the biomass trajectory until 2014 therefore covers primarily the period where thornback ray was not subject to TAC management but only to fisheries levels management such as gear and effort regulations.

Survey catchability of thornback ray in the Bay of Biscay was estimated to be around 0.13 . For the morphologically similar spotted ray (Raja montagui), Fraser et al. (2007) estimated a catchability of 0.15 in the International Bottom Trawl Survey in the North Sea which uses a similar bottom trawling as in the survey used here. Thus the estimated catchability seems reasonable.

The application of the SSM to thornback ray involved several strong assumptions for creating the landings time series but also for model formulation. By assuming that the time series of thornback ray landings followed that of all skates and rays, it was implied that the proportion of thornback ray in the landings of skates and rays remained constant. Larger skates such as white skate (Rostroraja alba) and those of the genus Dipturus are known to have severely declined (Dulvy et al. 2000; Dulvy and Reynolds 2002), which may have induced competitive release for medium-sized species such as thornback ray. However, at the same time the cuckoo ray (Leucoraja naevus), which represented about 3/4 of total landings of skates and rays in the Bay of Biscay in the last 10 years (ICES 2015), might have more benefited from this competitive release as it is a small bodied species, whose spatial distribution and depth range strongly overlaps with that of larger skates. As a result, the proportion of thornback ray in total ray landings could have been stable, as assumed here.

Carrying capacity $K$ and intrinsic growth rate $r$ were considered constant during the $20^{\text {th }}$ and early $21^{\text {st }}$ Century, that is during 111 years. This assumption was necessary in the absence of any information regarding how they might have varied. The intrinsic growth rate is the result of reproduction, individual body growth and natural mortality (Hoening and Gruber 1990), processes which are likely to vary with stock density and environmental conditions. Given their low and rather constant fecundity, elasmobranches may have low compensatory capacity (Kindsvater et al. 2016). Moreover, temperature in the Bay of Biscay has varied during the second half of the $20^{\text {th }}$ Century leading to a change in environmental conditions in the species' habitat (Michel et al. 2009). However, the Bay of Biscay is central in the latitudinal range of the thornback ray, so that temperature changes should not have evolved beyond what is suitable for the species. In contrast, natural mortality may have changed in either direction as a consequence of changes in biotic interactions driven by the overexploitation of numerous fish species and the depletion of some apex predators (Lorance et al. 2009). The population growth rate and carrying capacity may also have been impacted by long-term changes in benthic communities driven by fishing (Hiddink et al. 2011). However, these aspects are unknown for benthicfeeding rays. Changes in species composition of the benthos in favor of scavengers (Rumohr and Kujawski 2000) such as gastropods may have increased predation rates on ray and skate eggs (Lucifora and Garcia 2004). Lastly habitats in the Bay of Biscay have been modified by fishing and other human pres- sures, such as eutrophication in coastal waters (Lorance et al. 2009) but the effect of these habitat changes on skates and rays is unknown. In summary, carrying capacity and intrinsic growth rate of thornback rays in the Bay of Biscay might have varied or might have remained stable during the last century, we simply don't know.

All models are restricted by data availability and represent a trade-off between accuracy and complexity. The Bayesian state space biomass production model provided a useful framework for data integration in the case of data-poor stocks. In recent years, the amount of biological information has increased on growth, migration, mortality and spatial distribution of a number of ray and shark stocks in the Northeast Atlantic (e.g. Walker 1997; Hunter et al. 2005; Maxwell et al. 2009; Ellis et al. 2011; McCully et al. 2012; Martin et al. 2012). These data could be used to attempt estimating stock status of other thornback ray stocks and those of other elasmobranchs. Further, the development of a multispecies version of the model to assess simultaneously several elasmobranch stocks in a given area could be considered. Rajids species are closely associated ecologically and it is impossible to target species completely separately.

Acknowledgements. We acknowledge funding from the French "Agence Nationale de la Recherche" (ANR) for the GenoPopTaille project. FM thanks Ifremer for a Ph.D. studentship. We would like to thank three anonymous reviewers for constructive comments which helped to improve the manuscript.

\section{References}

Agnew D.J., Nolan C.P., Beddington J.R., Baranowski R., 2000, Approaches to the assessment and management of multispecies skate and ray fisheries using the Falkland Islands fishery as an example. Can. J. Fish. Aquat. Sci. 57, 429-440.

Bonfil R., 1994, Overview of world elasmobranch fisheries, FAO fisheries technical paper. FAO, Rome.

Camhi M., Pikitch E.K., Babcock E.A. (Eds.), 2008, Sharks of the open ocean: biology, fisheries and conservation, Fish and aquatic resources series. Blackwell Science, Oxford, Ames, Iowa.

Chevolot M., Hoarau G., Rijnsdorp A.D., Stam W.T., Olsen J.L., 2006, Phylogeography and population structure of thornback rays (Raja clavata L., Rajidae). Mol. Ecol. 15, 3693-3705.

Cope J.M., Thorson J.T., Wetzel C.R., DeVore J., 2015, Evaluating a prior on relative stock status using simplified age-structured models. Fish. Res. 171, 101-109.

Davidson L.N.K., Krawchuk M.A., Dulvy N.K., 2015, Why have global shark and ray landings declined: improved management or overfishing? Fish Fish. 17, 2, 438-458, June 2016.

Dorel D., Cadiou Y., Porcher P., 1998, Poissons, crustacés et mollusques des mers communautaires. Paramètres biologiques et représentations graphiques.

Du Buit M.H., 1974, Contribution à l'étude des populations de raies du Nord-Ouest Atlantique des Faeroe au Portugal (Sciences Naturelles). Université de Paris VI, Paris.

Dulvy N.K., Reynolds J.D., 2002, Predicting extinction vulnerability in skates. Conserv. Biol. 16, 440-450.

Dulvy N.K., Metcalfe J.D., Glanville J., Pawson M.G., Reynolds J.D., 2000 , Fishery stability, local extinctions, and shifts in community structure in skates. Conserv. Biol. 14, 283-293. 
Dulvy N.K., Fowler S.L., Musick J.A., Cavanagh R.D., Kyne P.M., Harrison L.R., Carlson J.K., Davidson L.N., Fordham S.V., Francis M.P., Pollock C.M., Simpfendorfer C.A., Burgess G.H., Carpenter K.E., Compagno L.J., Ebert D.A., Gibson C., Heupel M.R., Livingstone S.R., Sanciangco J.C., Stevens J.D., Valenti S., White W.T., 2014, Extinction risk and conservation of the world's sharks and rays. Elife. eLife.00590 3.

EC, 2009, COUNCIL REGULATION (EC) No. 43/2009 of 16 January 2009 fixing for 2009 the fishing opportunities and associated conditions for certain fish stocks and groups of fish stocks, applicable in Community waters and, for Community vessels, in waters where catch limitations are required.

Ellis J.R., Morel G., Burt G., Bossy S., 2011, Preliminary observations on the life history and movements of skates (Rajidae) around the Island of Jersey, western English Channel. J. Mar. Biol. Assoc. UK 91, 1185-1192.

Enever R., Catchpole T.L., Ellis J.R., Grant A., 2009, The survival of skates (Rajidae) caught by demersal trawlers fishing in UK waters. Fish. Res. 97, 72-76.

Figueiredo I., Moura T., Bordalo-Machado P., Neves A., Rosa C., Serrano Gordo L., 2007, Evidence for temporal changes in ray and skate populations in the Portuguese coast (1998-2003) - its implications in the ecosystem. Aquat. Living Resour. 20, 85-93.

Fraser H.M., Greenstreet S.P.R., Piet G.J., 2007, Taking account of catchability in groundfish survey trawls: implications for estimating demersal fish biomass. ICES J. Mar. Sci. 64, 1800-1819.

Frisk M.G., Miller T.J., Dulvy N.K., 2005, Life histories and vulnerability to exploitation of elasmobranchs: inferences from elasticity, perturbation and phylogenetic analyses. J. Northwest Atl. Fish. Sci. 35, 27-45.

Gelman A., Carlin J.B., Stern H.S., Dunson D.B., 2014, Bayesian data analysis, Chapman \& Hall/CRC texts in statistical science. 3rd edn., CRC Press, Boca Raton.

Geweke J., 1992, Statistics, probability and chaos: comment: inference and prediction in the presence of uncertainty and determinism. Stat. Sci. 7, 94-101.

Hammond T., Trenkel V., 2005, Censored catch data in fisheries stock assessment. ICES J.Mar. Sci.

Heessen H.J.L., 2003, Development of elasmobranchs stock assessment DELASS. Final report of DG Fish Study Contract 99/055.

Hiddink J.G., Johnson A.F., Kingham R., Hinz H., 2011, Could our fisheries be more productive? Indirect negative effects of bottom trawl fisheries on fish condition: Effects of bottom trawls on fish condition. J. App. Ecol. 48, 1441-1449.

Hilborn R., Walters C.J., 1992, Quantitative fisheries stock assessment: choice, dynamics, and uncertainty. Chapman and Hall, New York.

Hoening J.M., Gruber S.H., 1990, Life-history patterns in the elasmobranchs: implications for fisheries management (NOAA Technical Report No. NMFS 90), in Elasmobranchs as Living Resources: Advances in the Biology, Ecology, Systematics, and the Status of the Fisheries.

Holden M.J., 1972, The growth rates of Raja brachyura, R. clavata and $R$. montagui as determined from tagging data. ICES J. Mar. Sci. $34,161-168$.

Holden M.J., 1975, The fecundity of Raja clavata in British waters. ICES J. Mar. Sci. 36, 110-118.

Hunter E., Buckley A.A., Stewart C., Metcalfe J.D., 2005, Migratory behaviour of the thornback ray, Raja clavata, in the southern North Sea. J. Mar. Biol. Assoc. UK 85, 1095.

ICES, 2014a, Report of the Working Group on Elasmobranchs Fishes (WGEF) (No. ICES CM 2014/ACOM:19). Portugal, ICES, Lisbon.
ICES, 2014b, Thornback ray - ICES-FishMap.

ICES, 2015, Report of the Working Group on Elasmobranchs Fishes (WGEF) (No. ICES CM 2015/ACOM:19). Portugal, ICES, Lisbon.

IUCN, 2005, Malacoraja clavata: Ellis, J.: The IUCN Red List of Threatened Species 2005: e.T39399A10199527.

Kimura D.K., Tagart J.V., 1982, Stock Reduction Analysis, Another Solution to the Catch Equations. Can. J. Fish. Aquat. Sci. 39, 1467-1472.

Kimura D.K., Balsiger J.W., Ito D.H., 1984, Generalized stock reduction analysis. Canadian J. Fish. Aqua. Sci. 41, 1325-1333.

Kindsvater, H.K., Mangel, M., Reynolds, J.D., Dulvy, N.K., 2016. Ten principles from evolutionary ecology essential for effective marine conservation. Ecol. Evol. 6, 2125-2138.

Letaconnoux R., 1948, Effets de la guerre sur la constitution des stocks de poissons. Rapports et Procès-Verbaux des Réunions du Conseil Permanent International pour l'Exploration de la Mer $122,55-62$.

Lorance P., Bertrand J.A., Brind'Amour A., Rochet M.-J., Trenkel V.M., 2009, Assessment of impacts from human activities on ecosystem components in the Bay of Biscay in the early 1990s. Aquat. Living Resour. 22, 409-431.

Lucifora L.O., Garcia V.B., 2004, Gastropod predation on egg cases of skates (Chondrichthyes, Rajidae) in the southwestern Atlantic: quantification and life history implications. Mar. Biol. 145, $917-$ 922.

Martin C.S., Vaz S., Ellis J.R., Lauria V., Coppin F., Carpentier A., 2012, Modelled distributions of ten demersal elasmobranchs of the eastern English Channel in relation to the environment. J. Exp. Mar. Biol. Ecol. 418-419, 91-103.

Maurin H., 1994, Inventaire de la faune menacée en France. Muséum national d'Histoire naturelle, Paris.

Maxwell D.L., Stelzenmüller V., Eastwood P.D., Rogers S.I., 2009, Modelling the spatial distribution of plaice (Pleuronectes platessa), sole (Solea solea) and thornback ray (Raja clavata) in UK waters for marine management and planning. J. Sea Res. 61, 258-267.

McAllister M.K., Ianelli J.N., 1997, Bayesian stock assessment using catch-age data and the sampling - importance resampling algorithm. Can. J. Fish. Aqua. Sci. 54, 284-300.

McAllister M.K., Pikitch E.K., Babcock E.A., 2001, Using demographic methods to construct Bayesian priors for the intrinsic rate of increase in the Schaefer model and implications for stock rebuilding. Can. J. Fish. Aqua. Sci. 58, 1871-1890.

McCully S.R., Scott F., Ellis J.R., 2012, Lengths at maturity and conversion factors for skates (Rajidae) around the British Isles, with an analysis of data in the literature. ICES J. Mar. Sci. 69, 18121822.

McCully Phillips S.R., Scott F., Ellis J.R., 2015, Having confidence in productivity susceptibility analyses: A method for underpinning scientific advice on skate stocks? Fish. Res. 171, 87-100.

Michel S., Vandermeirsch F., Lorance P., 2009, Evolution of upper layer temperature in the Bay of Biscay during the last 40 years. Aquat. Living Resour. 22, 447-461.

Ono K., Punt A.E., Rivot E., 2012, Model performance analysis for Bayesian biomass dynamics models using bias, precision and reliability metrics. Fish. Res. 125-126, 173-183.

Parent E., Rivot E., 2013, Introduction to hierarchical Bayesian modeling for ecological data, Chapman \& Hall/CRC applied environmental statistics. CRC Press, Boca Raton.

Pauly D., Zeller D., 2016, Sea Around Us?: concepts, design and data (seaaroundus.org) Available at: http://www.seaaroundus.org (accessed 2.24.16). 
Plummer M., Best N., Cowles K., Vines K., 2006, CODA: Convergence Diagnosis and Output Analysis for MCMC. R News $6,7-11$.

Poulard J., Blanchard F., 2005, The impact of climate change on the fish community structure of the eastern continental shelf of the Bay of Biscay. ICES J. Mar. Sci. 62, 1436-1443.

Poulard J.-C., Trenkel V.M., 2007, Do survey design and wind conditions influence survey indices? Can. J. Fish. Aqua. Sci. 64, 15511562 .

Punt A.E., Hilborn R., 1997, Fisheries stock assessment and decision analysis: the Bayesian approach. Rev. Fish Biol. Fish. 7, 35-63.

Punt A.E., Su N.-J., Sun C.-L., 2015, Assessing billfish stocks: a review of current methods and some future directions. Fish. Res. $166,103-118$.

Quéro J.C., Cendrero O., 1996, Incidence de la pêche sur la biodiversité ichtyologique marine.

Quéro J.C., Guéguen J., 1981, Les raies de la mer celtique et du canal de Bristol. Abondance et distribution. Sci. Pêche. 318, 1-22.

Quéro J.C., Vayne J.J., 2005, Les poissons de mer des pêches françaises. Delachaux et Niestlé, Paris.

R Foundation for Statistical Computing, 2008, R Development Core Team (2008). R: A language and environment for statistical computing. Austria, Vienna.

Robert M., Faraj A., McAllister M.K., Rivot E., 2010, Bayesian statespace modelling of the De Lury depletion model: strengths and limitations of the method, and application to the Moroccan octopus fishery. ICES J. Mar. Sci. 67, 1272-1290.

Rochet M., Péronnet I., Trenkel V.M., 2002, An analysis of discards from the French trawler fleet in the Celtic Sea. ICES J. Mar. Sci. $59,538-552$.

Rumohr H., Kujawski, T., 2000, The impact of trawl fishery on the epifauna of the southern North Sea. ICES J. Mar. Sci. 57, 13891394.
Serra-Pereira B., Figueiredo I., Gordo L.S., 2011, Maturation, fecundity, and spawning strategy of the thornback ray, Raja clavata: do reproductive characteristics vary regionally? Mar. Biol. 158, 2187-2197.

Silva J.F., Ellis J.R., Catchpole T.L., 2012, Species composition of skates (Rajidae) in commercial fisheries around the British Isles and their discarding patterns. J. Fish Biol. 80, 1678-1703.

Steven G.A., 1931, Rays and Skates of Devon and Cornwall. Methods of Rapid Identification on the Fishmarket. J. Mar. Biol. Assoc. UK 17, 367.

Thomas A., O Hara B., Ligges U., Sturtz S., 2006, Making BUGS Open. R News 12-17.

Trenkel V.M., Bravington M.V., Lorance P., Walters C., 2012, A random effects population dynamics model based on proportions-atage and removal data for estimating total mortality. Can. J. Fish. Aquat. Sci. 69, 1881-1893.

Walker P., 1997, Distribution, movement and stock structure of three ray species in the North Sea and eastern English Channel. ICES J. Mar. Sci. 54, 797-808.

Walker P., Hislop J.R.G., 1998, Sensitive skates or resilient rays? Spatial and temporal shifts in ray species composition in the central and north-western North Sea between 1930 and the present day. ICES J. Mar. Sci. 55, 392-402.

Walker T., 1992, Fishery simulation model for sharks applied to the Gummy shark, Mustelus antarcticus Gunther, from Southern Australian waters. Mar. Freshw. Res. 43, 195.

Whittamore J.M., McCarthy I.D., 2005, The population biology of the thornback ray, Raja clavata in Caernarfon Bay, North Wales. J. Mar. Biol. Assoc. UK 85, 1089.

Wiegand J., Hunter E., Dulvy N.K., 2011, Are spatial closures better than size limits for halting the decline of the North Sea thornback ray, Raja clavata? Mar. Freshw. Res. 62, 722. 


\section{Appendix A}

BUGS code provided here is not optimized for calculation time but presented in the interests of clarity. \#FULL run model

model

\{

\#\#\#\#\#\#PRIORS\#\#\#\#\#\#\#

$\# N$ : Total number of years

\#Nf: number of years with research vessel CPUE

YQ dbeta $(17,4)$ I $(0.001$,$) \#Initial relative biomass$

K dunif $(20000,100000)$ \#Carrying capacity

r dbeta $(34,300) \mathrm{I}(0.01$,$) \#Intrinsic growth rate$

q dunif(0.01,0.5) \#Catchability

ytau2 dgamma $(400,1)$ \#1/Process error variance

$\mathrm{CV}<-0.2$

sigma2 $<-1 /$ ytau 2

uplim<-1+(3*sigma2)\#Upper bound for truncated normal

distribution

itau2 dgamma $(44,2)$

tau $2<-1 /$ itau 2

\#\#\#POPULATION DYNAMIC\#\#\#

Ymed $[1]<-Y Q$

for ( $t$ in $1: N$ )

\{

$\operatorname{Lmin}[\mathrm{t}]<-2 * \operatorname{Cobs}[\mathrm{t}] / \mathrm{K}$ \#Lower bound of the truncated normal ditribution

$\mathrm{Y}[\mathrm{t}] \sim \operatorname{dnorm}(Y \operatorname{med}[\mathrm{t}], \mathrm{ytau} 2) \mathrm{I}(\mathrm{Lmin}[\mathrm{t}], \mathrm{uplim})$

$\mathrm{ep}[\mathrm{t}]<-\operatorname{pow}(\mathrm{CV}, 2)+1$

invep $[\mathrm{t}]<-1 / \log (\mathrm{ep}[\mathrm{t}])$

$\log \operatorname{Cobs}[\mathrm{t}]<-\log (\operatorname{Cobs}[\mathrm{t}])$

$C[t] \sim \operatorname{dlnorm}(\log \operatorname{Cobs}[t], \operatorname{invep}[t]) I(\mathbb{Q}$,

Ymed $[\mathrm{t}+1]<-(\mathrm{r}+1) * \mathrm{Y}[\mathrm{t}]-(\mathrm{r} * \mathrm{Y}[\mathrm{t}]) * \mathrm{Y}[\mathrm{t}]-\mathrm{C}[\mathrm{t}] / \mathrm{K}$ 
$\operatorname{Imed}[\mathrm{t}]<-\mathrm{q} * \mathrm{Y}[\mathrm{t}] * \mathrm{~K}$

$\operatorname{Bmed}[\mathrm{t}]<-\mathrm{K} * \mathrm{Y}[\mathrm{t}]$

\}

$\mathrm{Y}[\mathrm{N}+1] \sim \operatorname{dnorm}(\operatorname{Ymed}[\mathrm{N}+1], \mathrm{ytau} 2) \mathrm{I}(\operatorname{Lmin}[\mathrm{N}], \mathrm{uplim})$

$\operatorname{Imed}[\mathrm{N}+1]<-\mathrm{q} * \mathrm{Y}[\mathrm{N}+1] * \mathrm{~K}$

$\operatorname{Bmed}[\mathrm{N}+1]<-\mathrm{K} * \mathrm{Y}[\mathrm{N}+1]$

for (i in $1: \mathrm{Nf}$ )

\{

LogImed [Index $[i]]<-\log (\operatorname{Imed}[\operatorname{Index}[i]])$

I [i] dlnorm(LogImed[Index[i]], itau2)

\}

$\mathrm{MSY}<-\mathrm{r} * \mathrm{~K} / 4$

\} \# end

\section{Appendix B}

a)

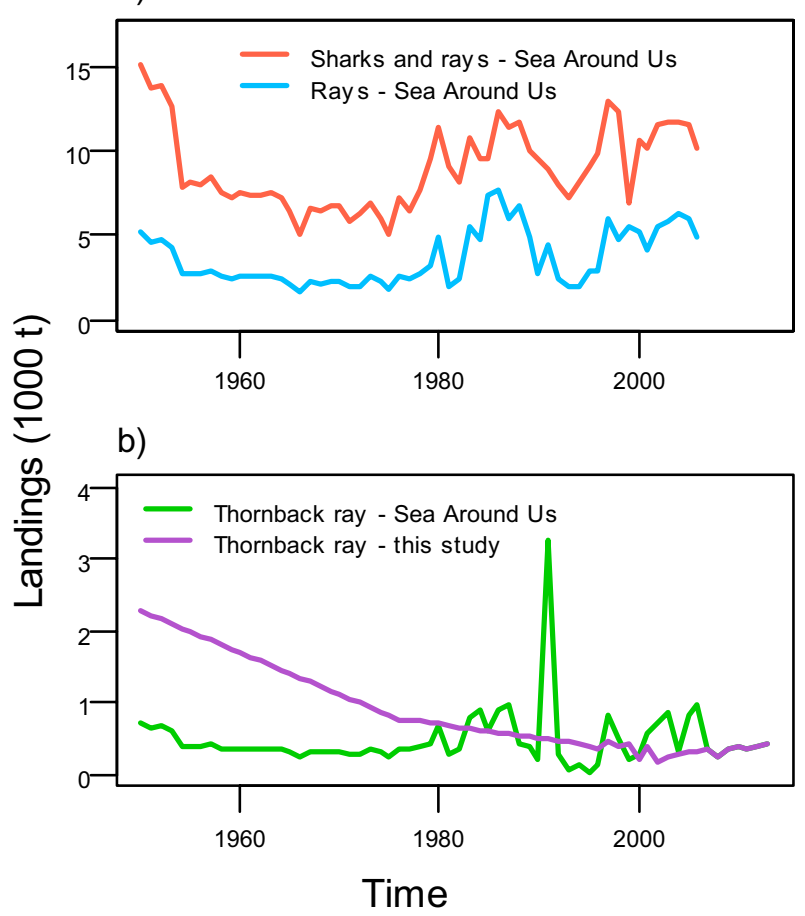

Fig. B.1. (a) Landings availables for sharks and rays species in the Bay of Biscay (red line) (Pauly and Zeller, 2016) and hypothetical rays landings in the Bay of Biscay (blue line). (b) Hypothetical landings for thornback ray in the Bay of Biscay used in this study (purple line) and alternative hypothetical landings for thornback ray in the Bay of Biscay based on Sea Around Us (green line) (Pauly and Zeller, 2016). 